\title{
WETTING AND DISPERSION IN CERAMIC/ POLYMER MELT INJECTION MOLDING SYSTEMS
}

\author{
Final Report
}

Submitted for: Grant No. DE-FG05-85ER45202 U.S. Department of Energy

\author{
Submitted by: $\quad$ Michael D. Sacks \\ Jerry W. Williams* \\ Department of Materials Science \\ and Engineering \\ University of Florida
}

\section{DISCLAIMER}

\begin{abstract}
This report was prepared as an account of work sponsored by an agency of the United States Government. Neither the United States Government nor any agency thereof, nor any of their employees, makes any warranty, express or implied, or assumes any legal liability or responsibility for the accuracy, completeness, or usefulness of any information, apparatus, product, or process disclosed, or represents that its use would not infringe privately owned rights. Reference herein to any specific commercial product, process, or service by trade name, trademark, manufacturer, or otherwise does not necessarily constitute or imply its endorsement, recommendation, or favoring by the United States Government or any agency thereof. The views and opinions of authors expressed herein do not necessarily state or reflect those of the United States Government or any agency thereof.
\end{abstract}

* Now with 3M Co., 3M Center, St. Paul, MN 


\section{TABLE OF CONTENTS}

\section{Page}

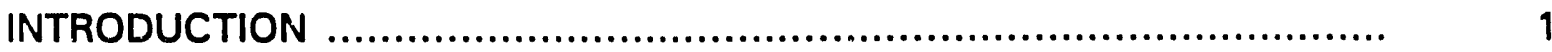

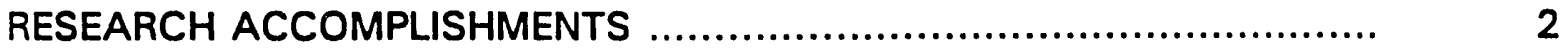

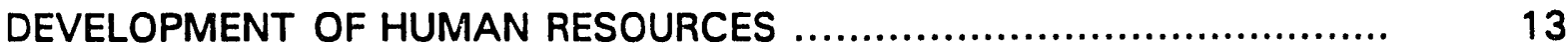

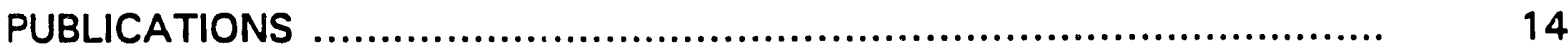

Cepuith kemoved 


\section{INTRODUCTION}

The following information is provided for the U.S. Department of Energy project entitled "Wetting and Dispersion in Ceramic/Polymer Melt Injection Molding Systems":

(1) A summary of research accomplishments attributed to this program.

(2) A statement concerning the development of human resources under this program.

(3) A list of publications resulting from this program. 


\section{RESEARCH ACCOMPLISHMENTS}

This program had two major areas of emphasis: (1) factors influencing the state of particulate dispersion and rheological properties of ceramic powder/polymer melt mixtures and (2) effect of interfacial bonding strength on the mechanical and rheological properties of ceramic particle/polymer composites. The research accomplishments in these areas are separately summarized below.

\section{A. Dispersion of Ceramic Particles in Polymer Melts}

The state of particulate dispersion in ceramic powder/polymer melt mixtures is important in forming nrocesses (such as injection molding) which are used in preparing bulk ceramic shapes. The state of dispersion is also important in processing of "filled" polymer composites, i.e., in which inorganic particles or fibers are incorporated into polymer matrices either to reduce the cost or to tailor the composite properties. The state of dispersion of the ceramic powder in the polymer melt (i.e., the distribution and packing of ceramic particles in the polymer) has a significant effect on the rheological properties of the ceramic/polymer mixture. The rheological properties control the flow behavior of the mixture during the injection molding operation. The state of dispersion also has a strong effect on the maximum solids loading (i.e., volume fraction of ceramic powder in the mixture) that can be achieved. In addition, the state of dispersion influences the polymer removal processes (e.g., via pyrolysis) that are part of the overall process of fabricating bulk ceramics. Transport of polymer molecules from the bulk ceramic powder/polymer samples is influenced by the pore size and size distribution formed by the packing arrangement of the ceramic particles. Thus, the polymer removal process is indirectly dependent on the dispersion state. Furthermore, the densification rate and the 
grain growth rate during sintering are strongly affected by the particle packing arrangement in the ceramic powder compact. Therefore, it is important to examine the dispersion of ceramic powders in polymer melts since it strongly influences each step in the processing sequence and ultimately affects the microstructure and properties of the final ceramic product.

In this study, the effects of mixing conditions and starting material properties on the state of dispersion in ceramic/polymer mixtures were investigated. Samples were prepared using a high shear bowl mixer and the mixing operations were monitored by a torque rheometar. The state of particulate dispersion was evaluated by (i) steady shear and dynamic (oscillatory) shear rheological measurements for samples heated to an elevated temperature and (ii) quantitative microscopy (QM) for samples cooled to room temperature. Wetting behavior at the ceramic/polymer interface was obtained by the sessile drop method and the polymer penetration method. Important results are summarized below.

\section{Mixing Conditions}

The effects of mixing variables, including time, temperature, and rotor speed, on the dispersion of alumina particles in polyethylene were investigated. The study was confined to a simple two-phase ceramic/polymer mixture without any chemical additives. Rheological flow measurements, torque rheometry, ceramic/polymer melt wetting behavior, and quantitative microscopic analysis were used to evaluate the effect of mixing variables on the state of dispersion. Microscopic analysis was based on the determination of a characteristic particle diameter, Dpc, which decreased in value as the state of dispersion improved. 
Samples mixed at higher temperatures $\left(175\right.$ and $\left.220^{\circ} \mathrm{C}\right)$ had higher viscosity and modulus values, higher yield stresses, extensive thixotropy, longer relaxation times, and larger Dpc values. These characteristics are typical for samples having a threedimensional particle network structure, suggesting that these samples were not dispersed well. In contrast, the samples mixed at lower temperatures $\left(125\right.$ and $\left.150^{\circ} \mathrm{C}\right)$ showed lower viscosity and modulus values, lower yield stresses, little hysteresis, shorter relaxation times, and smaller Dpc values, indicating that the particulate dispersion was improved by lowering the mixing temperatures. These differences were mainly caused by the temperature dependence of the polymer viscosity. Higher mixing torques were generated with the high viscosity polymer at lower mixing temperatures and, therefore, powder agglomerates were effectively broken down during the mixing operations. The benefit derived from the increased mixing torque, however, was partially offset by poorer wetting at lower temperatures. Hence, the mixing temperature should be low enough to develop large shear forces to break down agglomerates, but high enough so that wetting of the powder by the polymer melt is not adversely affected.

Results also showed that the mixing rotor speed should also be high enough to develop sufficient torque for agglomerate breakdown. It was also observed that mixing time did not affect particulate dispersion once the mixing torque reached a stable value (which was an indication that the maximum extent of agglomerate breakdown was achieved). In addition to agglomerate breakdown and powder/polymer wetting, stabilization of the particles against re-agglomeration (coagulation) was also important. Dynamic equilibrium between agglomerate breakdown and coagulation was established during the mixing operation. Using higher mixing temperatures or lower rotor speeds increased the coagulation rate, resulting in samples with poorer particulate dispersion. 
It was also found that the state of particulate dispersion could not be substantially improved (by lowering temperatures or raising rotor speeds) once the powders were coated with polymer.

\section{Ceramic Powder Characteristics}

Ceramic/polymer injection molding is affected by ceramic powder properties, such as particle size, size distribution, particle shape, etc. To some extent, these variables have been studied previously. However, the effect of ceramic surface hydroxylation on particle dispersion has not been investigated. In this part of the study, alumina powders were calcined at temperatures in the range of $100-1000^{\circ} \mathrm{C}$ prior to mixing with polyethylene in order to vary the amount of surface hydroxyl groups and adsorbed molecular water. The effects of calcination on dispersion and aging behavior were evaluated using rheological flow measurements, torque rheometry, infrared spectroscopy, hardness tests, particle size and specific surface area measurements, ceramic/polymer melt wetting behavior, and qualitative and quantitative microscopic analysis.

The calcined alumina powders $\left(100-1000^{\circ} \mathrm{C}\right.$ prior to mixing) could not be dispersed well in polyethylene melts compared to the uncalcined powder as indicated by higher viscosity, modulus, and Dpc values. During calcination, gradual removal of bound hydroxyl groups and adsorbed molecular water on the alumina surface was confirmed by gravimetric measurements and infrared spectroscopy. Calcination not only changed the powder surface properties, but also altered the mixing behavior (and, consequently, altered the state of particulate dispersion). The samples prepared with calcined powders were highly susceptible to aging effects when stored under ambient atmospheric conditions (i.e., in air at room temperature.). These samples showed decreases in 
viscosity and modulus values during the early stages of aging, followed by large increases in these values as the aging time was increased. This phenomenon was caused by moisture absorption from the atmosphere, which was confirmed by gravimetric and rheological measurements for samples aged in water. The initial decreases in viscosity and modulus values were possibly due to lubricating and/or plasticizing effects of the absorbed water in the samples. The subsequent large increases in viscosity and modulus values were caused by the formation of water vapor bubbles inside the alumina/polyethylene mixtures during rheological testing at elevated temperature $\left(125^{\circ} \mathrm{C}\right)$. This was confirmed by electron microscopy observations on the fracture surface of an aged (in water) and heated $\left(125^{\circ} \mathrm{C}\right.$ for $10 \mathrm{~min}$ ) sample. The bubbles acted as a second dispersed phase in the mixtures, resulting in an increase in the effective volume fraction of the non-fluid phase in the sample.

\section{Polymer Characteristics}

The ceramic/polymer rheological behavior can be altered significantly by varying polymer properties. In this part of the study, experiments were carried out using polymers with different functional groups: polyethylene (PE), ethylene-acrylic acid (EAA), and ethylene-vinyl acetate (EVA). The influence of polymer chemistry on the properties of the ceramic/polymer mixtures was investigated by rheological measurements on the polymer melts and ceramic/polymer mixtures, ceramic/polymer melt wetting behavior, quantitative microscopic analysis, and torque rheometry.

Alumina/polymer mixtures prepared with polyethylene (PE) and ethylene-acrylic acid (EAA) had similar rheological properties and Dpc values, while mixtures prepared with ethylene-vinyl acetate (EVA) had higher viscosity (especially at low frequencies) and larger 
Dpc values. These results suggested that particulate dispersion was similar for the PE and EAA samples, while EVA samples were not as well dispersed. Based on the limited range of chemical compositions investigated, the amount of the functional side group in the polymer had little effect on the state of dispersion achieved. Instead, the type of functional side group had an important effect on the state of dispersion achieved. However, correlations between mixing torque curves, particulate dispersion, and wetting behavior were not always straightforward.

\section{Chemical Additives}

Chemical additives can be used to modify the ceramic/polymer interface and thereby alter the state of dispersion and composite properties. In this part of the study, several coupling agents, surfactants, and fatty acids were used to modify the dispersion of alumina particles in polyethylene. The role of these chemical additives was investigated using several techniques, including torque rheometry, dynamic shear rheological measurements, wetting measurements, Fourier transform infrared spectroscopic characterization of treated powders, etc. All of the chemical additives were added to the alumina powder prior to the polymer/powder mixing operation. Thus, the physicochemical characteristics of alumina powders were modified by the suspension preparation and drying steps used to incorporate the additives.

Coupling Agents. A correlation was observed between the peak torque values during powder/polymer mixing and the degree of particulate dispersion observed in the coating suspensions (i.e., the suspensions prepared for coating the alumina powders with coupling agents). Larger torque peaks were generated when polyethylene was mixed with

the alumina powders prepared from well-dispersed suspensions (silane Z-6020 and 
zircoaluminate). In contrast, smaller torque peaks were observed when polyethylene was mixed with alumina powders prepared from flocculated coating suspensions (silane Z6076 and titanate). The former powders had more densely-packed agglomerates and smaller pore sizes. Thus, the initial incorporation of these agglomerates into the polymer melts was difficult, resulting in higher peak torque values. In contrast, the latter powders had a greater percentage of large pore channels. Thus, the initial incorporation of the powders into the polymer melts occurred easily, resulting in lower peak torque values. Based on the rheological data and the quantitative microscopy results, samples prepared with the silane Z-6020 and zircoaluminate coupling agents had relatively good dispersion, while the samples prepared with the silane Z-6076 and titanate coupling agents were poorly dispersed. These results confirmed the previous conclusion that large stresses generated during mixing were crucial in breaking down the powder agglomerates.

In steady shear measurements, all samples prepared with coupling agent-treated alumina had lower shear stress values and lower viscosities at higher shear rates (compared with the sample containing untreated alumina powder). Possible reasons for this behavior incluoied improved ceramic/polymer wetting and/or increased slip during the measurements; however, no supporting evidence was obtained in this study. Stress relaxation data were consistent with other rheological measurements, except that a long stress relaxation time was observed for the sample with silane Z-6020-treated alumina. The reason for this behavior was not understood, but available evidence suggested that the stress did not relax because the sample adhered to the stainless steel rotor plate of the viscometer.

Surfactants. Samples prepared with the surfactant Fluorad FC-740 showed similar behavior to samples prepared with coupling agents in that similar relationships were 
observed between the peak torque values during mixing, the degree of particulate dispersion for the coating suspensions, and the state of particulate dispersion for the alumina/polymer mixtures. The 0.6 vol\% Fluorad suspension was well dispersed and the 6.0 vol\% Fluorad suspension was flocculated. As a result, $\mathrm{OM}$ and rheological data showed that the alumina/polymer sample with 0.6 vol\% Fluorad (which had a high peak torque during mixing) developed excellent particulate dispersion. In contrast, the alumina/polymer sample with 6.0 vol\% Fluorad (which had low peak torque during mixing) was poorly dispersed.

Lubricants. There were no clear correlations between the rheological characteristics of the coating suspensions, the peak torque values during mixing, and the state of particulate dispersion in mixed batches. The shear stresses increased for the coating suspensions in the order $0.6<2.0<0.2$ vol\% stearic acid, while the peak torque values decreased significantly for samples prepared with stearic acid additions. The dynamic viscosity, modulus, and average Dpc values increased for samples in the order $0.6<0.2<2.0$ vol\% stearic acid. Stress relaxation and steady-shear rheological measurements were generally consistent with the conclusions drawn from the Dpc and dynamic-shear rheological data. It was possible that some type of lubricating and/or wetting effect was operative when stearic acid was added. C.ontact angle measurements showed that wetting behavior was improved by stearic acid additions $(0.2-2.0$ vol\%).

To avoid possible differences in powder characteristics caused by the initial coating treatment (i.e., preparation of coating suspensions with varying amounts of stearic acid and subsequent drying), experiments were also carried out by adding untreated alumina powders directly to polymer melts containing different amounts of stearic acid 10.2-2.0 vol\%). The mixing curves were similar to those of samples prepared using pretreated 
powders. Once again, peak torque values decreased as the stearic acid concentration increased. These samples also showed relatively poor dispersion after mixing. The mixing method had relatively minor effects on the Dpc values and rheological properties.

\section{B. Effects of Interfacial Bonding on the Properties of Silica/EVA Polymer Composites}

The properties of particulate-filled polymer composites are highly dependent upon the interfacial bonding between the filler particles and polymer matrix. In present study, a model system was utilized which allowed for both (i) control over molecular interactions which determine the interfacial bonding and (ii) quantitative characterization of interfacial bonding. The strength of the interfacial bonding was characterized in terms of the work of adhesion between the filler particles and polymer matrix. Following the approach of Fowkes and coworkers, the work of adhesion was partitioned into two contributions, i.e., (i) hydrogen and/or polar forces and (ii) dispersion forces. The effect of work of adhesion on the mechanical and rheological properties of the filler/polymer composites was investigated.

In this study, the filler material was silica ar.d the polymer was polyethylene-vinyl acetate (EVA). Interfacial bonding was modified by surface treatments of the silica filler particles. In particular, surface silanol concentrations on the particles were modified by heat treatment and/or chemical treatment with trimethylchlorosilane. Since silanol groups can form hydrogen bonds with the carbonyl groups in the polymer molecular chain, it was possible to vary the hydrogen and/or polar contribution of work of adhesion by changing the concentration of surface silanol groups.

The interfacial properties for the silica/EVA samples were investigated using infrared spectroscopy, contact angle measurements, and titration experiments. The 
dispersion component and the hydrogen and polar components of the surface energy for the silica and the EVA polymer were determined from contact angle measurements. The concentration of hydroxyl groups on silica surfaces was determined by titration experiments using indicator dyes. Diffuse reflectance Fourier Transform Infrared Spectroscopy (DRIFT) was used to determine the extent of hydrogen bonding on the silica surface and to determine the type of bonding between the silica surface and the EVA copolymer. Work of adhesion was determined using Fowkes' equation. The tensile strength and modulus of silica/EVA composites were determined at room temperature from stress-strain tests carried out with an Instron tester. The rheological properties (modulus and viscosity) of the samples were determined in a dynamic mode loscillatory shear) at elevated temperature using a Rheometrics Dynamic Spectrometer.

The effects of interfacial bonding on the mechanical and rheological properties of the composites were studying using varying silica volume fraction and particle size and varying testing conditions (e.g., temperature, measuring frequency). The work of adhesion $\left(\mathrm{W}_{\mathrm{a}}\right)$ was varied over the range $63-301 \mathrm{erg} \mathrm{cm}^{-2}$ by modifying the silica surface characteristics. $W_{a}$ decreased with increased heat treatment temperature for untreated powders. This was attributed to decreased hydrogen bonding, i.e., due to decreased surface hydroxyl group concentration for the silica filler. Further decreases in $\mathrm{W}_{\mathrm{a}}$ were observed when silica powders were treated with trimethylchlorosilane (TMCS). This was associated with further decreases in surface hydroxyl concentration, thereby resuiting in even less hydrogen bonding. The component of the work of adhesion due to hydrogen and/or polar forces $\left(W_{a}{ }^{h}\right)$ varied over the range $13-260 \mathrm{erg} \mathrm{cm}^{-2}$, following the same trends as observed for $W_{a}$. In contrast, the dispersion component $\left(W_{a}{ }^{d}\right)$ of the work of adhesion showed relatively little dependence upon surface treatment, varying only 
over the range $41-53 \mathrm{erg} \mathrm{cm} \mathrm{cm}^{-2}$. Thus, the variation in $\mathrm{W}_{\mathrm{a}}{ }^{\mathrm{h}}$ was the main factor influencing observed changes in mechanical and rheological properties of the silica/EVA composites.

The mechanical and rheological properties of the polymer composites were dependent on the materials characteristics (e.g., particle sizes and volume fractions of fillar) and test conditions (e.g., measuring frequencies and temperatures). At a constant vollume fraction of silica filler, the elastic modulus, tensile strength, dynamic shear modulus and dynamic viscosity of the composites $\mathrm{w}$ gre directly proportional to $\mathrm{W}_{\mathrm{a}}$. With increasing filler volume fraction, modulus and viscosity values increased and tensile strength values decreased. At constant filler volume, samples prepared with a Cab-O-Sil silica (finer size, more aggregated particles) had higher modulus, viscosity, and strength values compared to samples prepared with Stober silica (iarger size, less aggregated particles). 


\section{DEVELOPMENT OF HUMAN RESOURCES}

This program provided support for research carried out by two Ph.D. students and one postdoctoral associate:

(1) Shaye-Wen Shang obtained his Ph.D. in Materials Science and Engineering from University of Florida in 1989. Dr. Shang is currently employed by HIMONT USA, Inc. in Pasadena, Texas.

(2) Joan-Huey Dow obtained her Ph.D. in Materials Science and Engineering from University of Florida in 1992. Dr. Dow is currently employed by ALZA Corp. in Palo Alto, CA.

(3) Dr. Aroon V. Shenoy carried out postdoctoral research in the Department of Materials Science and Engineering at the University of Florida (from February 1986 to December 1987). He is currently on the faculty in the Department of Energy and Mechanical Engineering at Shizuoka University in Japan.

During the term of this program, support was also provided for undergraduate research carried out by H.L. Chew. 


\section{PUBLICATIONS RESULTING FROM THIS PROGRAM}

M.D. Sacks, C.S. Khadilkar, G.W. Scheiffele, A.V. Shenoy, J.-H. Dow, and R.S. Sheu, "Dispersion and Rheology in Ceramic Processing," pp. 495-515 in Ceramic Powder Science, Advances in Ceramics, Vol. 21, edited by G.L. Messing, American Ceramic Society, Westerville, Ohio, 1987.

J.W. Williams and S.-W. Shang, "Effect of Work of Adhesion on the Mechanical Properties of Silica Filled Ethylene-Vinyl Acetate Copolymer Composite," Polymer Prpt., 28 (2) 44-45 (1987).

J.-H. Dow, M. D. Sacks, and A. V: Shenoy, "Dispersion of Ceramic Particles in Polymer Melts," pp. 380-388 in Ceramic Powder Science II, A, Ceramic Transactions, Vol. 1, edited by G.L. Messing, E.R. Fuller, and H. Hausner, American Ceramic Society, Westerville, Ohio, 1988.

J.W. Williams, S.W. Shang, and M.D. Sacks, "Quantitative Studies of the Effect of Adhesion on the Mechanical and Physical Properties of Polymer Composites," pp. 17-23 in fudhesion in Solids, Mat. Res. Soc. Symp. Proc. Vol. 119, edited by D.M. Mattox, C. Batich, J.E.E. Baglin, R.J. Gottschall, Materials Research Society, Pittsburgh, PA, 1988.

S.-W. Shang, "Quantitative Studies of the Effects of Interfacial Bonding Strength on the Mechanical and Rheological Properties of Polymer Composites," Ph.D. Dissertation, Univ. of Florida, 1989.

J.-H. Dow, M.D. Sacks, and A.V. Shenoy, "Dispersion of Alumina Particles in Polyethylene Melts," pp. 431-442 in Ceramic Powder Science III, Ceramic Transactions, Vol. 12, edited by G.L. Messing, S.-I. Hirano, and H. Hausner, American Ceramic Society, Inc., Westerville, OH, 1990.

J.-H. Dow, "Dispersion of Ceramic Particles in Polymer Melts," Ph.D. Dissertation, University of Florida, 1992.

S.W. Shang, J.W. Williams, and K.-J.M. Soderholm, "Using the Bond Energy Density to Predict the Reinforcing Ability of a Composite," J. Mater. Sci., 27 4949-4956 (1992).

J.-H. Dow, M.D. Sacks, and A.V. Shenoy, "Effect of Mixing Conditions on the Dispersion of Alumina Particles in Polyethylene," to be submitted to J. Appl. Poly. Sci.

J.-H. Dow, M.D. Sacks, and P.H. Holloway, "Method for Determination of the State of Particulate Dispersion in Ceramic Powder/Polymer Mixtures," to be submitted to J. Am. Ceram. Soc.

J.-H. Dow and M.D.Sacks, "Effect of Powder Calcination on the Properties of Alumina/ Polyethylene Mixtures," in preparation.

J.-H. Dow and M.D. Sacks, "Aging Effects in Alumina/Polyethylene Mixtures," in preparation.

J.-H. Dow and M.D. Sacks, "Effect of Coupling Agents on the Particulate Dispersion and Rheological Properties of Alumina/Polyethylene Mixtures," in preparation.

J.-H. Dow and M.D. Sacks, "Effect of a Fluorocarbon Surfactant on the Particulate Dispersion and Rheological Properties of Alumina/Polyethylene Mixtures," in preparation.

J.-H. Dow and M.D. Sacks, "Effect of Stearic Acid on the Particulate Dispersion and Rheological Properties of Alumina/Polyethylene Mixtures," in preparation. 

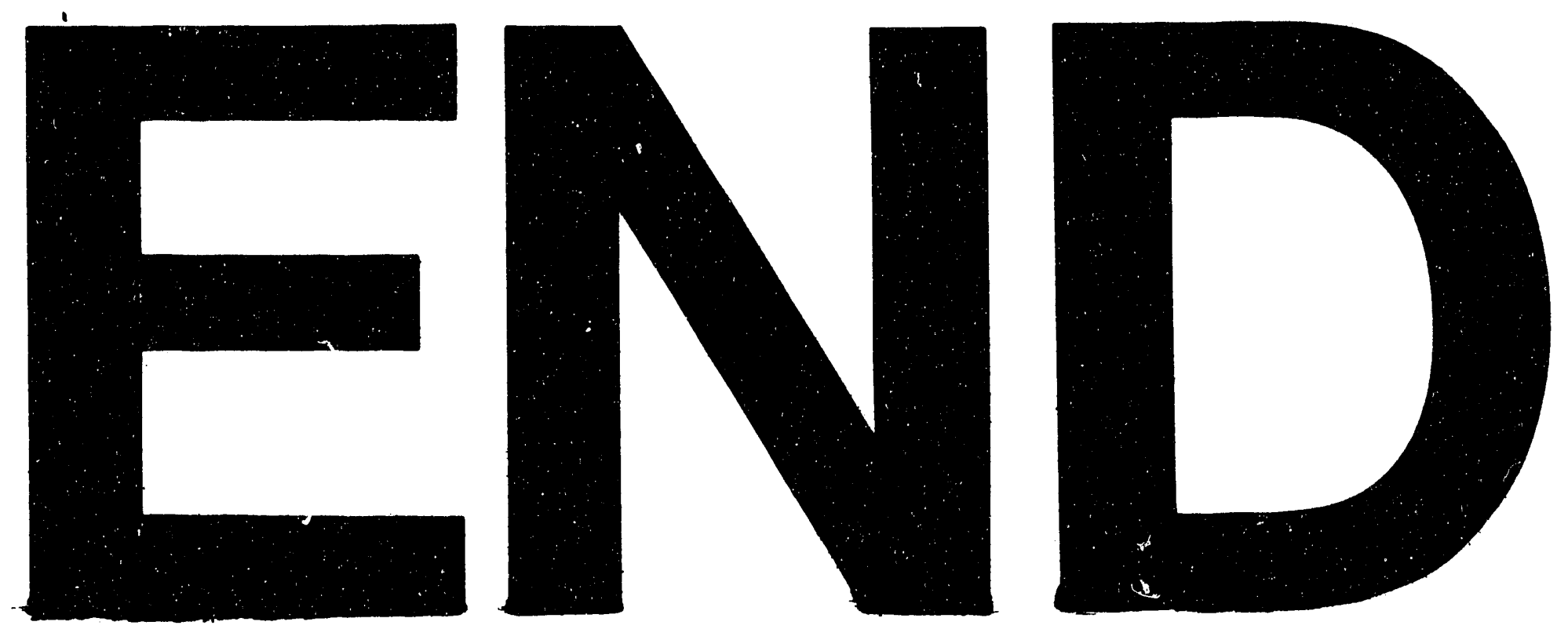

$\therefore$

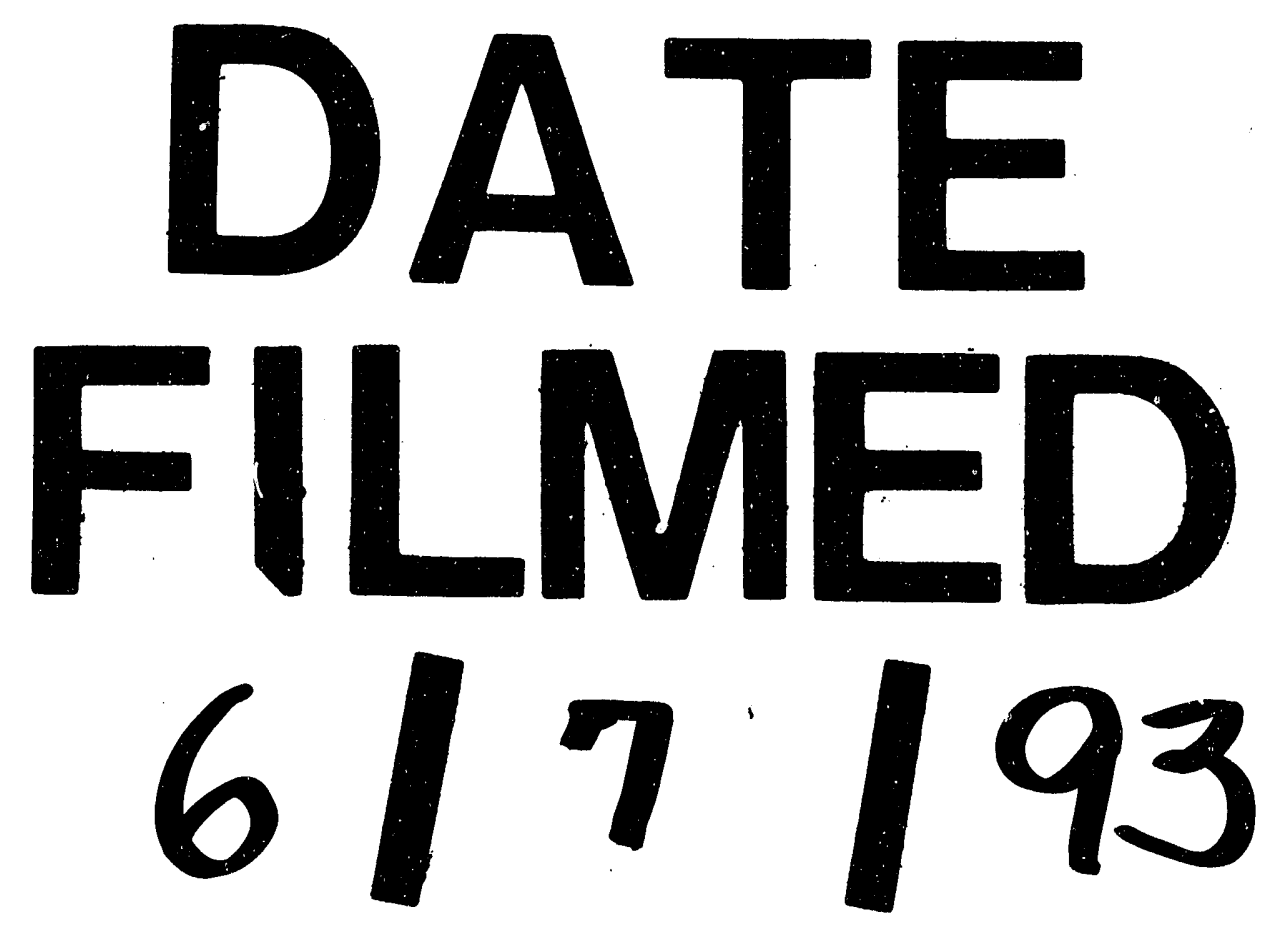




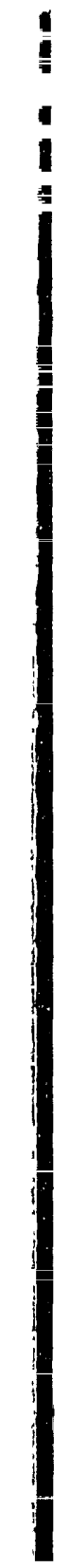

